\title{
Constructing change: how socially responsible procurement is changing the construction industry
}

Public procurement in construction has long been considered a method of both acquiring goods and services, but also creating socio-economic benefits. These benefits can come in the form of employment opportunities, often in areas typically bereft of options for lower educated or non-service-based job seekers. They can also support local markets, and improve the inclusion of ethnic, religious or LGBTQ minorities. These types of procurement are typified as responsible, due to their multiple benefits that are not always found in private-sector procurement, where lowest cost is often the only factor in consideration. Within the EU, responsible procurement is enshrined in law under Clause 18:2 - the "respect for Human Rights" in the "fields of Environmental, Social and Labour Law". Socially responsible procurement (SRP) is found in a similar field to corporate social responsibility (CSR), but does not have the same issues with needing public opinion to force the hand of shareholders.

The Public (Social) Value Act (2012) brought into law the power of SRP, which came into force in Northern Ireland in 2016 . Here, all public building contracts worth over $£ 2 \mathrm{~m}$, and all civil engineering contracts worth over $£ 4 \mathrm{~m}$ required adherence this Act, promoting employment opportunities to the long-term unemployed (LTU), improved working conditions, ethical trade and social inclusion provision. This is the foundation of SRP, but there are issues. Such restrictions and regulations can stifle innovation and growth, and hinder expansion and profitability in construction companies. There are also issues around enforcing employment within LTU demographics, and the potential discrimination against non-national suppliers. Yet the benefits SRP can offer seem to outweigh the potential issues, it is just the case that more work needs to be done to fine-tune the implementation.

\section{Innovating construction}

The introduction of SRP to the construction industry in the EU has had the same seismic shift on processes as the introduction of health and safety requirements did in the previous decades. SRP's effect can be recognized as a service innovation - described by Murphy and Eadie (2019) as a new method of delivering services, often outside of the primary agent's traditional area of expertise, often encompassing both technical and organizational innovation. In this sense, SRP represents a wholly new element to procurement and construction. Within this industry there are few who would have experience of engaging the LTU demographic, or putting a CSR element into procurement. Yet by being forced to do so, there are possibilities to radically alter aspects of the construction industry in ways that may not be obviously beneficial at the outset, but ultimately result in significant improvements.

Within the construction industry, specifically those involved in government contracts, roles have been created due to this innovation such as community benefits managers. KPIs have had to change too, as they now have to account for measurements of social value performance targets. These have forced construction organizations into altering their financial models in order to accommodate costs involved with social value - typically a non-profit-making activity. There are issues, however, with the implementation of SRP in construction. Construction organizations are typically poorly set-up for socially focused

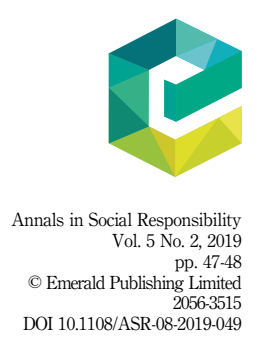


ASR

5,2

activities, and badly implemented social initiatives can often do more harm than good. It is also forcing a traditionally cut-throat and profit-driven industry to think about doing things not for their own benefit. Whilst this is positive and potentially hugely beneficial for others, it could cause conflicts between those who seek advantage in order to survive, and those who understand the need to think about society's gain too. It could also add additional costs that ultimately make the organizations not competitive and therefore liable to be challenged and potentially shunted out of the market. Nonetheless SRP, if it is enforced by the government and its clients at all levels, could ultimately have a profoundly positive effect on an industry that, in many ways, needs to prove it can think about the society for which it builds, and not just its own bottom line.

\section{Comment}

The review is based on "Socially responsible procurement: a service innovation for generating employment in construction" by Martina Murphy and Robert Eadie (2019).

\section{Reference}

Murphy, M. and Eadie, R. (2019), "Socially responsible procurement: a service innovation for generating employment in construction", Built Environment Project and Asset Management, Vol. 9 No. 1, pp. 138-152. 